\title{
INTEGRAL INDEX OF OPERATION QUALITY FOR EVALUATION OF IMPACT OF DISTRIBUTIVE GENERATION SOURCES ON ELECTRIC NETWORK MODES
}

\author{
Petro D. Lezhniuk' ${ }^{1}$, Vyacheslav O. Komar' ${ }^{1}$, Dmytro S. Sobchuk ${ }^{2}$, \\ Vira V. Teptia ${ }^{1}$, Michalina Gryniewicz-Jaworska ${ }^{3}$ \\ 1 Department of Electric Power Stations and Systems, Vinnytsia National Technical University, 95 Khmelnitskoye \\ Shose, Vinnytsia, 21021, Ukraine \\ 2 Department of Electricity Supply, Lutsk National Technical University, 75 Lvivska, Lutsk, 43018, Ukraine \\ ${ }^{3}$ Lublin University of Technology, Department of Grid Network and Security, Nadbystrzycka 36 Str, 20-618 \\ Lublin, Poland, e-mail: michalina.gryniewicz.jaworska@vp.pl
}

Received: 2017.02.07

Accepted: 2017.04.26

Published: 2017.06.01

\begin{abstract}
Method of operation quality evaluation of electric network, comprising renewable sources of energy (RSE) is considered. Integral index that enables to evaluate the impact of RSE on energy losses and its quality as well as balance reliability in electric network is suggested. Mathematical model is constructed, taking into account the assumption that electric network with RSE may be in various operation modes, characterized by different technical economic indices. To determine the integral index of operation quality of electric network with RSE in all possible states tools of Markov processes theory and criterial method are used.
\end{abstract}

Keywords: electric network, renewable, renewable sources of energy, operation quality, integral index.

\section{INTRODUCTION}

Nowadays intensive studies are performed in the sphere of intellectualization of power industry. Development of Smart Grid technologies opens new possibilities for the control of electric energy systems operation modes, distributed generation development, efficient consumption of electric energy. Within the frame of Smart Grid concept the variety of demands of all the parties concerned is reduced to such key issues of power industry as availability, reliability, economic efficiency, ecological safety and security $[1,8,9,10]$. In the conditions of transition from centralized energy supply to combined supply the application of Smart Grid technologies enables to reach a compromise between all the participants of energy market.
The approaching of energy sources to the consumers potentially may improve technical economic indices of operation both of electric network (EN) and consumers of electric energy. Main component of distributed generation is renewable sources of energy (RSE): small hydroelectric stations (SHES), solar electric plants (SEP) and wind electric plants (WEP). As operation mode of WES depends on natural conditions, then it is not always possible to obtain positive technical economic effect both for energy supply company and consumers of electric energy. To solve the problems, emerging in the process of introduction of distributed generation sources, it is necessary to elaborate indices that could be applied for evaluation of their impact on operation quality of energy supply systems. 
Irrespective of the peculiarities of energy supply the consumer must obtain the electric energy of corresponding quality with guaranteed level of reliability. One of the most important indices of energy quality is voltage deviation. For the investigation of electric energy quality indices in 2000 IEEE formed a team of specialists, the results of the work of this team are available in $[2,3]$. Analysis of consumers sensitiving to voltage quality is shown in [4]. Operation mode and reliability of both the source of electric energy and electric network have direct impact on voltage deviations. It is obvious that separate evaluation of voltage quality and reliability may lead to incorrect conclusion. As, for instance, introduction of electric energy source close to the consumer may have positive impact on voltage quality but the reliability may decrease as a result of the appearance of additional element that may become the reason of the failure in electric network. The authors of the research [5] draw attention to such cases, analysing the investments in the sphere of electric energy quality increase. That is why, it is necessary to evaluate the operation of electric networks by complex index. This complex index for evaluation of voltage deviation impact on consumers operation, that is determined, taking into account the indices of reliability and economic efficiency of the consumers, is suggested in $[6,11,12]$.

The given research develops the integral index to evaluate the impact of distributed generation sources on the quality of electric networks operation. Operation quality is the ability of elec- tric networks with distributed sources of energy to provide reliable and qualitative energy supply of consumers. Unlike complex index the integral index not only characterizes several properties but also shows the relation of these properties to "ideal" state of the system. Integral index gains maximum value for the case, close to optimal. That is why, it is possible to realize certain measures only till integral index grows. This property can be used during the analysis of operation quality and the ways of its improvement.

\section{INTEGRAL INDEX OF OPERATION QUALITY}

Electric networks with the sources of distributed generation are redundant systems. Failure of the elements of such systems does not lead to the failure of the whole system but transfers it into a new state that is characterized by the worsening of operation characteristics. Taking into account this fact, the problem of operation quality evaluation of electric network with renewable sources of energy could be divided into subproblems by means of the division of electric network operation process into separate states. Within the limits of each state operation quality characteristics influenced by distributed sources of energy, may be analyzed (see Fig. 1). Transition from one state into another state is realized with $v$ intensity.

Quality of electric network operation is characterized by the quality of electric energy, its losses in the network and reliability of energy supply of the consumers by the sources, connected to the

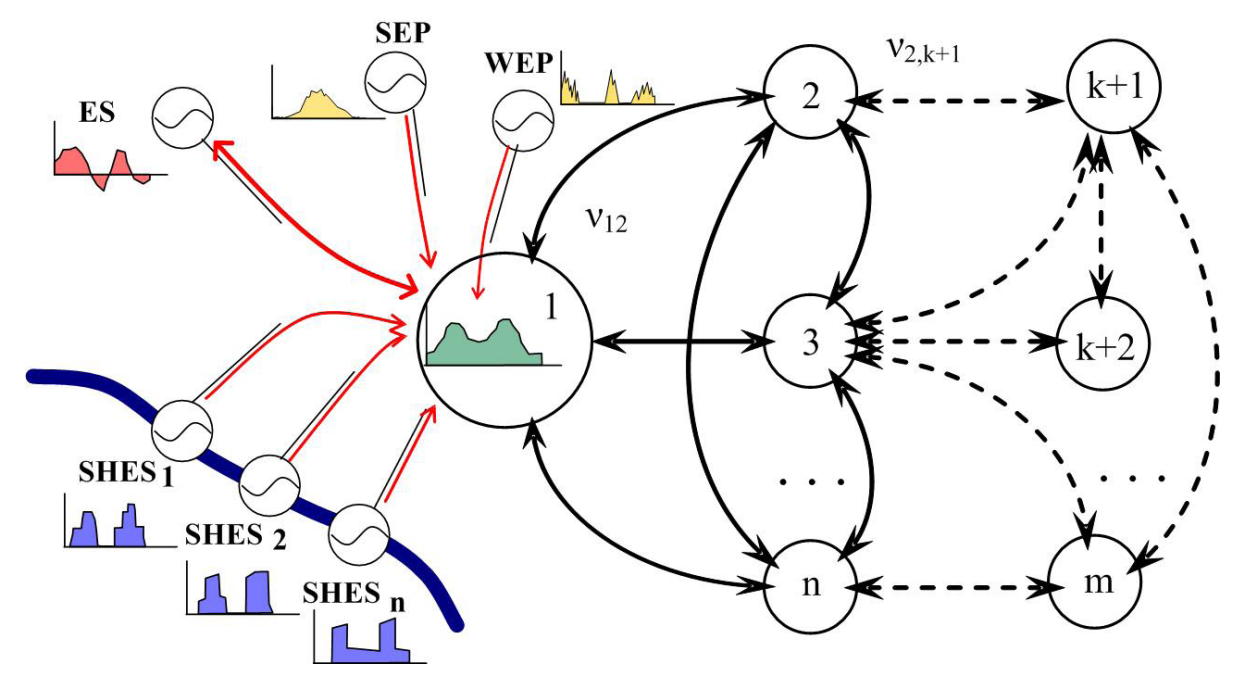

Fig. 1. Graphic interpretation of the integral index of electric network with distributed generation operation quality evaluation 
network. To determine these characteristics, the calculation of steady-state mode for each operating state is performed; by the results of such calculation voltage deviations, energy supply schedule provision and energy losses are analyzed.

Depending on the ratio of RSE generated power and consumed power on the feeder, to which the source is connected, the quality of power can vary. Voltage quality is suggested to be evaluated by the coefficient of voltage quality:

$$
k_{u}=\prod_{j \in N} p_{u j}
$$

where: $\mathrm{j}-$ is the number of loading node from the set of nodes $\mathrm{N}$, where voltage is controlled; $p_{u j}-$ is the probability that the voltage in the node $\mathrm{j}$ during period $\mathrm{T}$ is within admissible range $U_{\max }-U_{\min }$.

Probability $\mathrm{p}_{\mathrm{uj}}$ may be defined by the formula:

$$
p_{u j}=\frac{\sum_{s=1}^{z} \Delta t_{s}}{T}
$$

where $\Delta \mathrm{t}_{\mathrm{s}}=\mathrm{t}_{\mathrm{q}}-\mathrm{t}_{\mathrm{q}-1}-$ are time intervals, during which the voltage is within admissible range; $\mathrm{z}-$ is total amount of such time intervals.

Figure 2 illustrates the method of time intervals $\Delta \mathrm{t}_{\mathrm{s}}$ determination. Moments $\mathrm{t}_{\mathrm{q}-1}$ and $\mathrm{t}_{\mathrm{q}}$ define the time of voltage determination in admissible range.

To take into consideration the economic component of electric network with RSE operation we recommend to introduce losses coefficient $k_{L}$, that corresponds to the probability of determination of active power losses deviation within the norm

$$
k_{L}=p_{L}
$$

where $\mathrm{p}_{\mathrm{L}}-$ is the probability of determination of active power losses deviation in the network within the norm during period $\mathrm{T}$.

Probability $\mathrm{p}_{\mathrm{L}}$ may be defined by the expression

$$
p_{L}=\frac{\sum_{s=1}^{m} \Delta t_{s}}{T}
$$

Figure 3 illustrates the method of time intervals $\Delta \mathrm{t}_{\mathrm{s}}$ determination. Moments $\mathrm{t}_{\mathrm{q}-1}$ and $\mathrm{t}_{\mathrm{q}}$ determine the time of losses search in norm area.

Analysis of daily graphs allows to speak about the absence of coincidence between the graphs of RSE generation and loading that negatively influences the balance provision. Growth of RSE

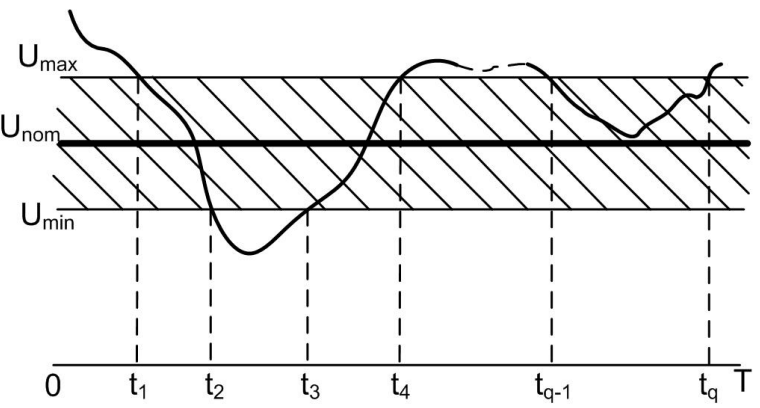

Fig. 2. Graph of voltage change in the node and range of admissible limits of their change

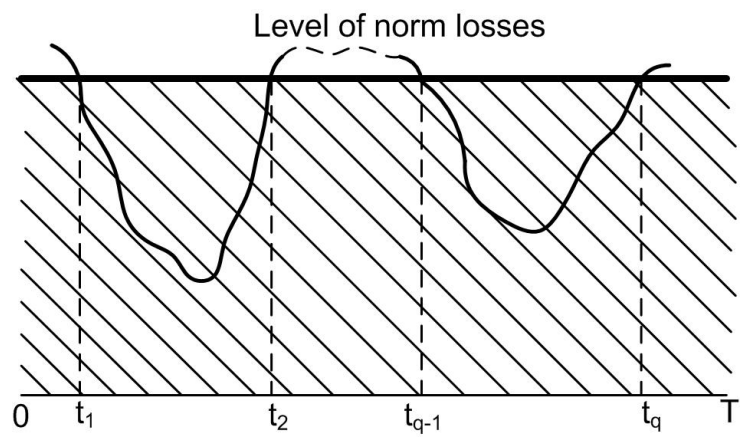

Fig. 3. Graph of active power losses deviation change in the network during period $\mathrm{T}$ and area of norm boundaries of their change

power may partially improve balance reliability but this can negatively influence voltage quality. Controversial impact of RSE may be taken into account by means of introducing the coefficient of balance provision $\mathrm{k}_{\mathrm{b}}$, that is characterized by electric energy during time $T$ :

$$
\left\{\begin{array}{c}
\text { if } \quad M(\Delta W) \geq 0 ; \quad k_{b}=1-\frac{M(\Delta W)}{M\left(W_{C}\right)} \\
\text { if } M(\Delta W)<0 ; \quad k_{b}=1
\end{array}\right.
$$

where $\mathrm{M}\left(\mathrm{W}_{\mathrm{C}}\right)$ - is mathematical expectation of electric energy consumption; $\mathrm{M}(\mathrm{W})-$ is mathematical expectation of non-correspondence of generation and consumption of electric energy during time $\mathrm{T}$.

Taking into account the suggested coefficients index of operation quality of certain state of distribution electric network with RSE will have the form:

$$
k_{q}=k_{u} k_{L} k_{b}
$$

Values of the coefficients of concordance to the norms of the values of voltage, energy losses and electric energy balance providing characterize quality of electric network in certain state. 
Completely operational (ideal) state of electric network with RSE is the state, when the values of all the coefficients equal one. In this case the coefficient of operation quality of the network with RSE $\mathrm{k}_{\mathrm{q}}=1$. In other states of the network with RSE $\mathrm{k}_{\mathrm{q}}<1$.

To determine the integral operation quality index of electric network with RSE in all possible states, we may apply the method, based on combination of the theory of Markov processes and criterial method [7]. In accordance with this method, taking into consideration (6), integral index of operation quality is determined by the expression:

$$
E=\sum_{i=1}^{m}\left(P_{i} \cdot k_{q i}\right)
$$

where: $P_{i}-$ is the probability of electric network with RSE in i state stay (is determined by means of solution of the system of Kalmogorov-Chapman equations, that consists of the intensities of transitions $\mathrm{v}$ of EN with RSE from state to state); $\mathrm{k}_{\mathrm{q}}-$ is the index of system operation quality in state $i ; m-$ is the amount of possible states of the investigated system.

Index of EN with RSE operation quality, determined by (7), enables to evaluate quantitatively relative readiness of distribution electric networks to perform their functions of qualitative and reliable energy supply of consumers, as compared with "ideal" network.

\section{MEANS OF THE ANALYSIS OF QUALITY INDICES OF ELECTRIC NETWORKS WITH DISTRIBUTED GENERATION OPERATION AND THE EXAMPLE OF THEIR APPLICATION}

To analyze the results of calculation of integral indices of electric network with RSE operation quality, that take into account level of electric energy losses in electric network and other parameters, characterizing technical state of the networks and technical economic efficiency of their operation, the program of graphic analysis was elaborated. The program of graphic analysis provides the possibility of presentation:

- character of distribution of integral index of EN with RSE operation quality, depending on the point of connection and power of the latter;

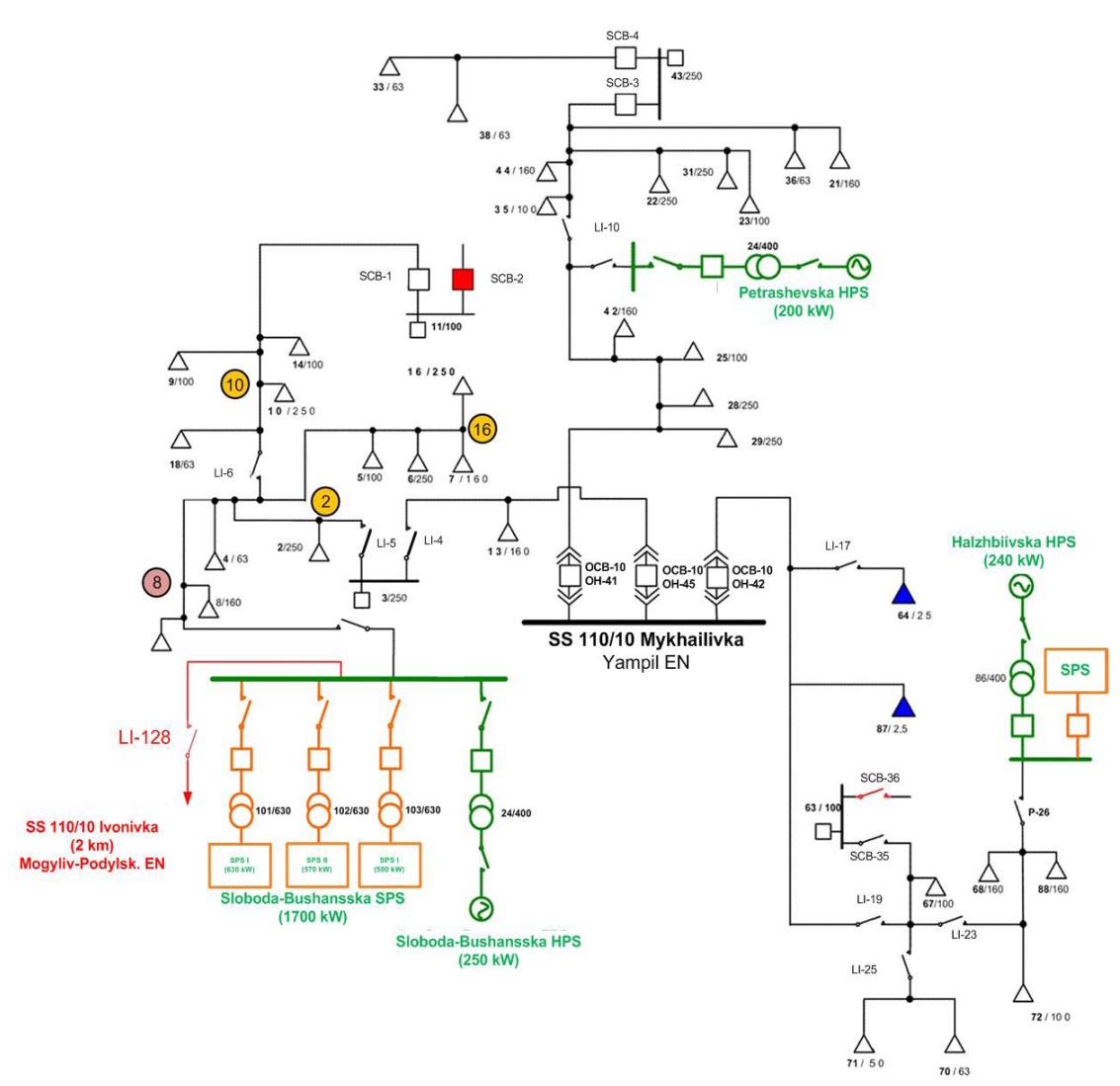

Fig. 4. Fragment of $10 \mathrm{kV}$ electric network with RSE 


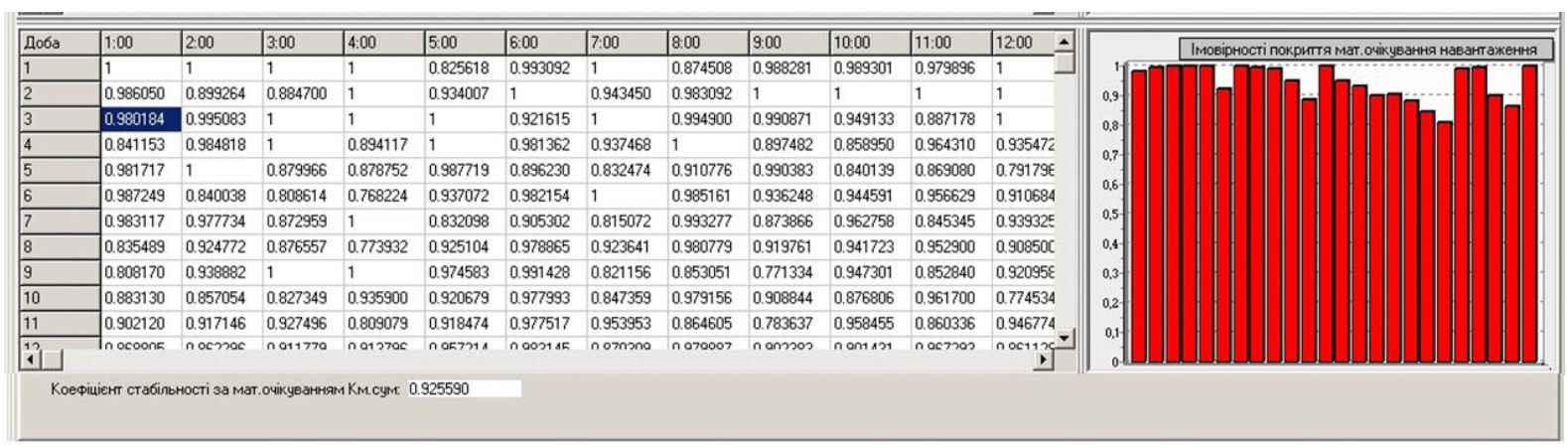

Fig. 5. Results of balance provision coefficient determination

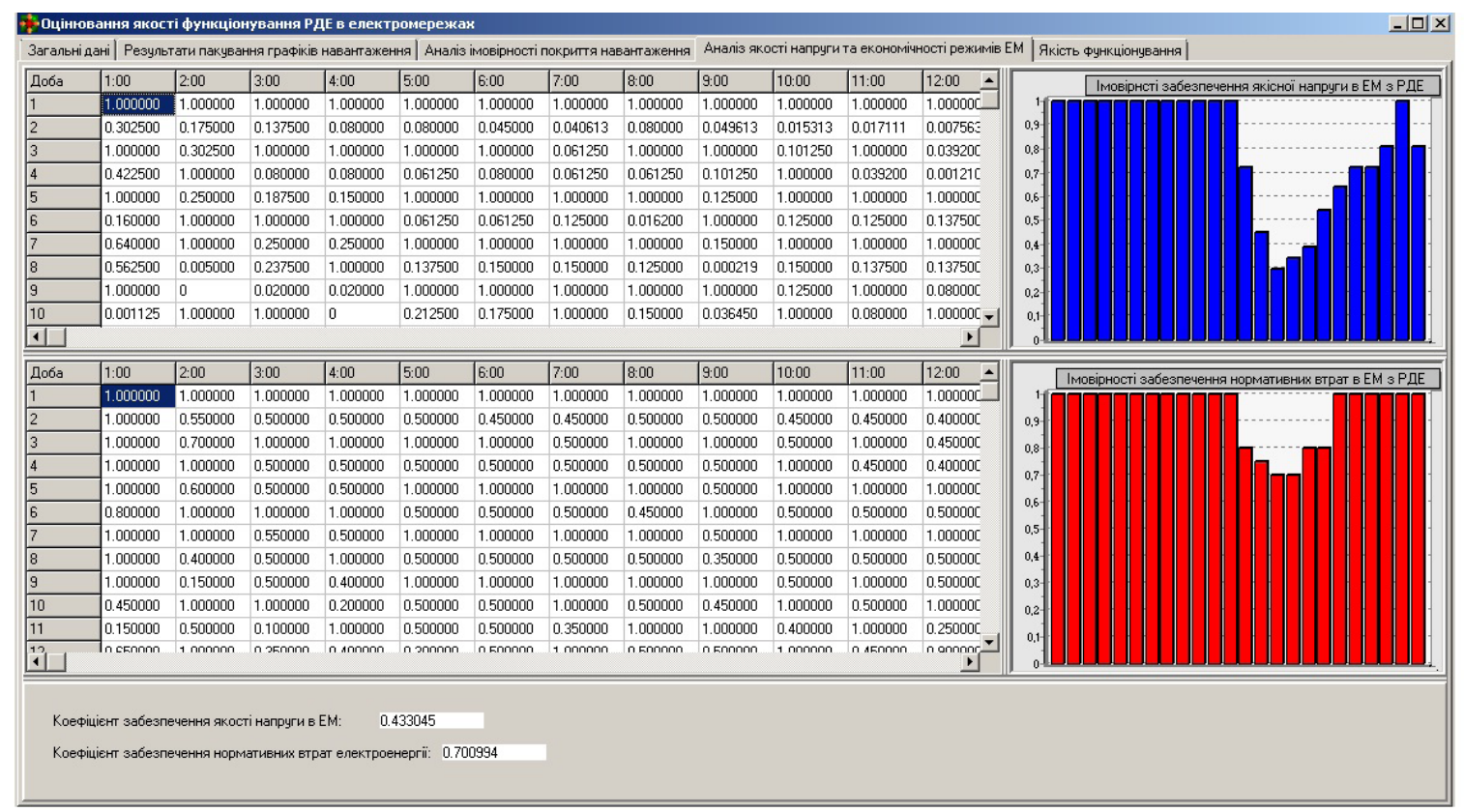

Fig. 6. Results of voltage quality coefficient determination

- results of ranging of possible points of RSE connection to the network, depending on the value of integral index of its operation quality.

As an example, we will consider the electric network with renewable sources of energy (see Fig. 4). Perform the evaluation of the operation quality index. Select the best place for the connection of solar electric plant (SEP) choosing from nodes $10,16,2,8$ by the integral index of operation quality. Use the program of graphic analysis, according to the formed graph of possible states, perform the analysis of the balance provision coefficient change (Fig. 5), voltage quality coefficient (Fig. 6) and integral index of operation quality (Fig, 7). Value of losses coefficient is taken as one, if the connection of SEP to electric network did not lead to losses increase. In other cases losses coefficient de- creases by the same value in relative units as energy losses in the network increase after SEP connection.

For the example, the scheme of which is given in Figure 4, for the comparison we will define the value of integral index of quality prior to introduction of SEP $(E=0,876)$ and after introduction of SEP $(\mathrm{E}=0,41)$ (see Fig.8). Decrease of quality index is explained by the overloading of the feeder 45. After introduction of $1700 \mathrm{~kW} \mathrm{SEP} \mathrm{electric} \mathrm{energy} \mathrm{losses} \mathrm{and}$ voltage in the lines of feeder 45 of substation (SS) "Mykhailivka", where 250 kW small HPS already operates, increased. It is possible to unload feeder 45 if the switch LI-128 is turned on. Part of the power will be delivered to substation "Ivonivka" of the neighboring district electric network. As a result of electric energy 


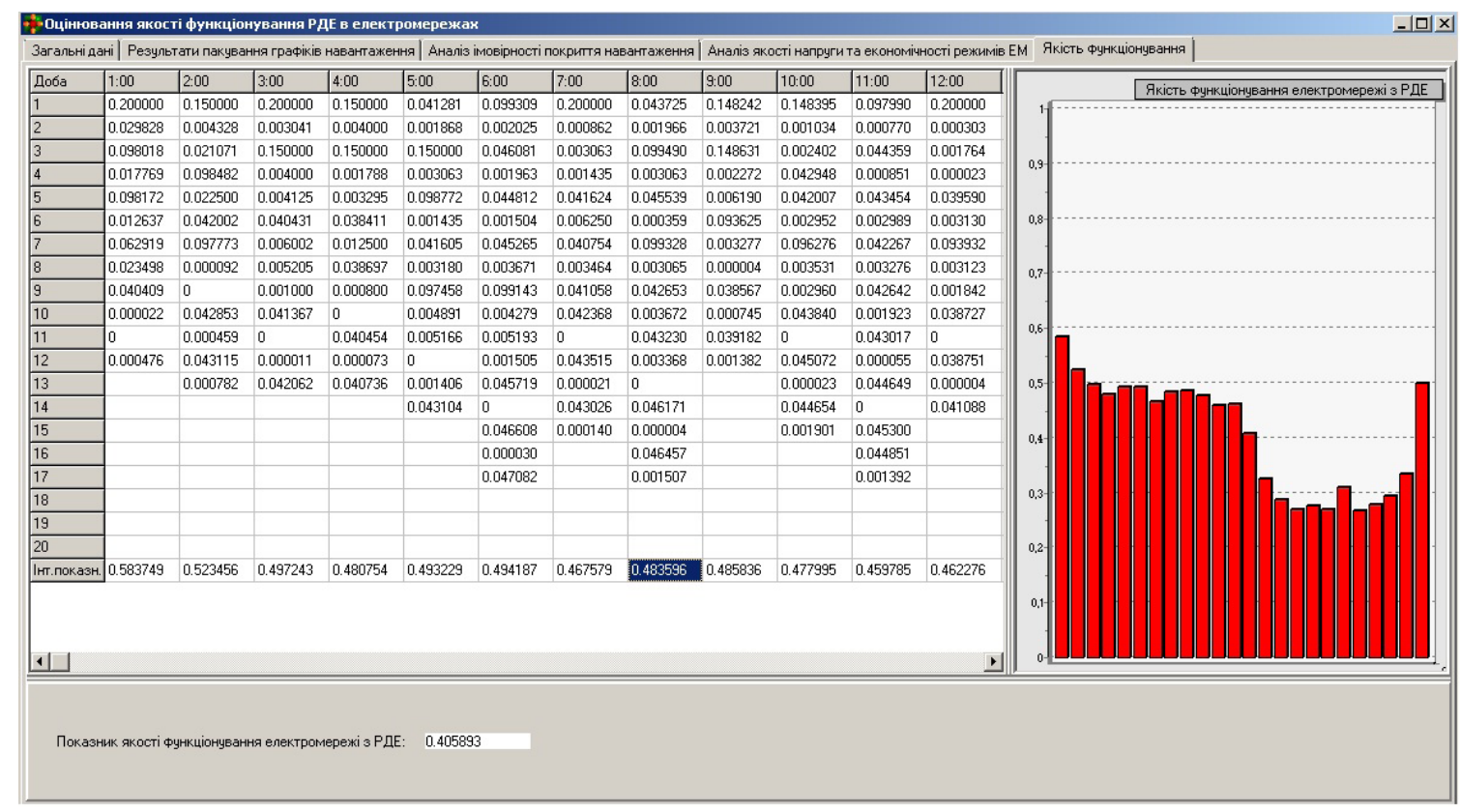

Fig. 7. Graphic analysis of EN with distributed generation operation quality

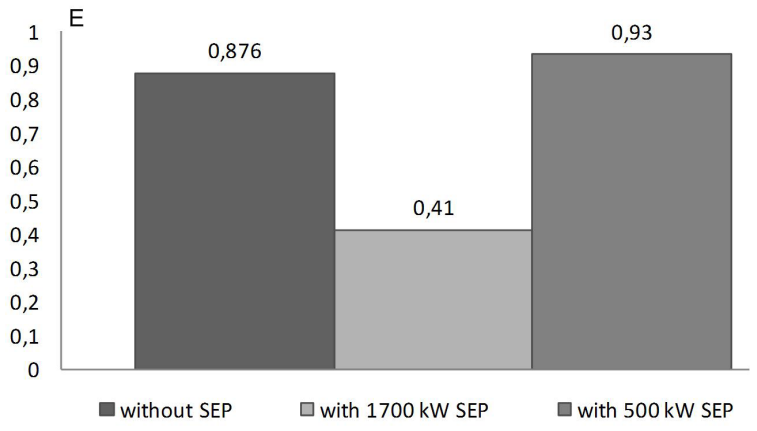

Fig. 8. Results of the integral index of operation quality evaluation

and voltage losses reduction and improvement of reliability aggregate technical economic efficiency of electric networks and RSE will grow. Transmission of the part of SEP power to substation "Ivonivka" allowed to increase positive effect at the feeder $45(\mathrm{E}=0,93)$.

\section{COST EVALUATION OF THE QUALITY OF DISTRIBUTION ELECTRIC NETWORKS}

According to the suggested index of operation quality the transition to the analysis of technical economic efficiency could be realized. The volume of electric energy, the consumer will receive less or of low quality can be determined by the obtained index of operation quality:

$$
\bar{W}=(1-E) \cdot W
$$

As the expenses for covering losses as a result of a poor quality of electric energy and its undersupply are different, then the problem arises to single out the component from the total volume of electric energy, determined by (8).

This problem could be solved analyzing (7) taking into account quality of electric energy E" and without it $\mathrm{E}^{\prime}$. According to (8) the volume of undersupply energy will be determined as:

$$
\bar{W}^{\prime}=\left(1-E^{\prime}\right) \cdot W
$$

and the volume of electric energy of poor quality

$$
\bar{W}^{\prime \prime}=\left(E^{\prime}-E^{\prime \prime}\right) \cdot W
$$

Thus, by the values of losses, undersupply, electric energy of poor quality and their costs, cost evaluation of the considered variant of RSE introduction was carried out.

Integral index of quality must be easily decomposed into component indices and combined into generalized indices. It is rather easy to realize due to the principles, embedded in the process of mathematical dependency construction (7). From the expression (7) partial provision indices of electric energy quality, normative expenditures and balance reliability can be obtained and from these indices we may pass to monetary expression. From practical experience it is seen that for 


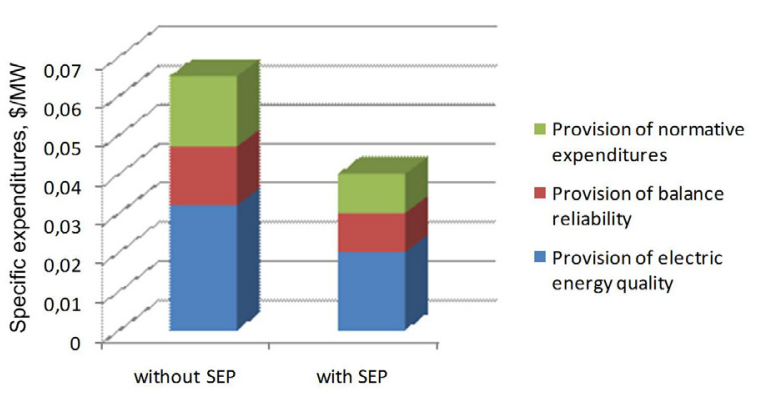

Fig. 9. Possible expenditures for energy supply of the consumers (expenditures are reduced to one hour)

operation staff of electric networks monetary expression of operation quality components is more comprehensible. However, the transition to monetary expression is more cumbersome and is exposed to certain subjectivity. Necessary calculations were performed for the considered example. Figure 9 shows the results of such calculation; judging by these result certain cheapening of energy supply for transport company almost by 0.03 $\$ / M W$ can be stated due to introduction of SEP.

\section{CONCLUSIONS}

The suggested method of quality index evaluation of electric network with RSE operation allows to determine its functional readiness to provide reliable and efficient energy supply. The index allows to evaluate the impact of RSE on functional readiness of electric networks. Mathematical models of voltage quality, energy supply schedule provision and active power losses account coefficients are developed. Analysis of evaluation results of functional possibilities of real existing electric network with SEP and small HPS showed the adequacy of the suggested model of operation quality index.

\section{REFERENCES}

1. Bahadoorsingh S., Milanovic J.V., Zhang Y., Gupta C.P. Minimization of voltage sag costs by optimal reconfiguration of distribution network using genetic algorithms, IEEE Trans. Power Delivery, vol.
22, (4), 2007, 2271-2278.

2. Burbelo M., J., Pijarski P., Zavadskiy V., Koczorowska-Gazda A., Lyudmyla M. Melnychuk L. M., Loboda Y. V. Measurement of reactive power under asymmetrical nonsinusoid modes of electric networks with earthed neutral. Proceedings of SPIE, nr 10031. 2016.

3. Farghal S.A., Kandil M.S., Elmitwally A. Quantifying electric power quality via fuzzy modeling and analytic hierarchy processing, IEE Proceedings of Generation, Transmission and Distribution, vol. 149(1), 2002, 44-49.

4. Guanghou Jin, Gengyin Li, Ming Zhou, Yixin Ni, Research on allocation of gross electromagnetic pollution emission right in power quality markets, IEEE Power Engineering Society General Meeting, 2005, 320-325.

5. Kacejko P., Machowski J., Pijarski P.: Standing phase angle reduction at switching operation in transmission network. Rynek Energii nr 5(96), 2011, 4-35.

6. Kacejko P., Pijarski P. Cost sharing on the network upgrade individual investors applying for connection to a network of wind farms . Przegląd Elektrotechniczny, NR 9a (88), 2012, 27-31.

7. Kacejko P., Pijarski P.. Connecting of wind farms limitations instead of oversized investment. Rynek Energii nr 1(80), 2009, 10-15.

8. Kacejko P., Pijarski P.: Dynamic Fitting of Generation Level to Thermal Capacity of Overhead Lines. Przegląd Elektrotechniczny, R.84 (5), 2008, 80-83.

9. Kanitpanyacharoean W, Premrudeepreechacharn S. Power quality problem classification using wavelet transformation and artificial neural networks, TENCON (3), 2004, 252-255.

10. Lezhnyuk P. D., Komar V. O., Kravtsov K. I. Criterion of function quality estimation of distribution networks [Electronic resource]. Scientific Works of Vinnytsia National Technical University .Nr 3, 2008. Mode of access.: http:/works.vntu.edu.ua/ index.php/works/article/view/85/85.

11. Smart Power Grids - Talking about a revolution. IEEE Emerging Technology portal, 2009. 2011. [Electronic resource] - Mode of access: http://www.ieee.org/portal/site/emergingtech/techindex.jsp?techId=1220

12. Yang X, Li G. Comprehensive Assessment of Voltage Sag Considering Reliability and Economy, Sustainable Power Generation and Supply, SUPERGEN '09. International Conference 2009. 